\title{
SURFACE-RUNOFF CHARACTERISTICS UNDER SIMULATED RAINFALL CONDITIONS
}

\author{
P. Das ${ }^{1}$, K. Mahmud ${ }^{*}$ and S. Karmaker ${ }^{1}$ \\ Department of Irrigation and Water Management, Bangladesh Agricultural University \\ Mymensingh-2202, Bangladesh
}

\begin{abstract}
This paper describes a rainfall-runoff simulation study, conducted in a laboratory to investigate surface runoff characteristics, verify unit hydrograph assumption and investigate the nature of the recession constant. A hydrology bench consisting of a metallic tray with an over head sprinkler system was used for this study. The metallic tray with soil bed and a river network acted as a small catchment. The over head sprinkler system consisting of spray nozzles acted as rainfall simulator. Different rainfall intensities and durations were taken as the treatments for the experiments. Surface runoff volume was collected at 10 secondly pulses of time in each experiment. Collected data were then processed and analyzed to explain the results. Unit hydrographs were developed from the surface runoff hydrographs for different rainfall durations and intensities. Recession constant $\mathrm{K}$ was calculated from the recession limb of each surface runoff hydrograph by optimization. Investigations show that runoff volume, runoff generation rate and peak runoff rate increase with the increasing rainfall duration. However, the peak runoff rate per sec of effective rainfall decreases with the increasing rainfall duration. There is also an evidence of the effects of rainfall intensity on runoff characteristics but no specific trend is identified. This study also reveals that the assumption of linearity between runoff volume and hydrograph ordinates is partially valid with some error which may be attributed to the non-uniform distributions of rainfall. Nature of recession constant suggests that the recession hydrograph is not only a function of catchment characteristics but also depends on rainfall intensities.
\end{abstract}

Key Words: Simulated rainfall, Surface-runoff, Unit hydrograph, Recession constant

\section{INTRODUCTION}

An important question in hydrology is how much stream flow occurs in a river in response to a given amount of rainfall. To answer this question we need to know where water goes when it rains, how long does water reside in a watershed, and what pathway does water take to the stream channel. Answering these questions can give us a clear understanding about the rainfall-runoff processes, or more generally surface water input-runoff processes.

1Post-graduate Students, 2 Lecturer, Department of Irrigation and Water Management, Bangladesh Agricultural University, Mymensingh-2202, Bangladesh

*Corresponding author (Email: khalid84bau@gmail.com) 
Rainfall-runoff processes constitute active and deep areas of research in hydrology. These processes are well described in literature. Numerous papers on these processes have been published and many computer simulation models have been developed. All these models, however, require detailed knowledge of a number of factors and initial boundary conditions in a catchment area, which in most cases are not readily available. The experimental investigations can therefore be performed for a better understanding of the difficulties of accurately predicting the amount of runoff resulting from a rainfall event. Moreover, controlled experiments under simulated rainfall conditions for studying rainfallrunoff processes are not new concept in hydrology.

Experiments to evaluate rainfall-runoff relation and soil erosion have been conducted under simulated rainfall conditions in different countries of the world. Joshi and Tambe (2010) measured the effect of slope and grass-cover on infiltration rate, runoff and sediment yield under simulated rainfall conditions and showed that highest runoff as well as sediment yield, as expected, were generated from the bare badland slopes and lowest from grass covered area with gentle slope. A laboratory experiment for studying runoff and sediment generation processes under different coverage of grass plots in simulated rainfall conditions showed that grass cover significantly reduced runoff and sediment compared to the bare soil plots (Pan and Shangguan, 2006). Sayed and Habib (2008) conducted a research on advanced technique for rainfall-runoff simulation by a physically based distributed model in arid catchment of Sinai, Egypt and highlighted the complexity of rainfall-runoff processes in arid regions especially under the constraints of limited information on rainfall variability and the significant heterogeneity in watershed properties and model parameters.

In Bangladesh this sort of researches are very rare. In this work, surface runoff characteristics under different conditions of simulated rainfall were studied in the laboratory. Some basic analyses on unit hydrograph were also incorporated in the study. The specific objectives of this study were to investigate (i) the behaviors of surface runoff generated from simulated rainfall, (ii) the validity of the principle of linearity as assumed in the unit hydrograph and (iii) the nature of the recession constant under variable runoff magnitudes.

\section{MATERIALS AND METHODS}

\section{Hydrology bench}

This study was conducted during January to June 2013 using a locally made hydrology bench in the hydraulic laboratory of Bangladesh Agricultural University. The hydrology bench consisted of a sand/soil filled metallic tray to act as a micro catchment and an overhead sprinkler device to act as a rainfall simulator. The metallic tray was $211.0 \mathrm{~cm}$ long, $108.0 \mathrm{~cm}$ wide and $16.5 \mathrm{~cm}$ deep, filled layer by layer with dry and sieved soils of different textures (Fig. 1(a)). The top layer consisted of comparatively fine soil to represent the surface soil and the bottom layer consisted of very coarse material to permit subsurface flow. A network of micro-river system was created on the top of the soil bed to represent a natural river system. Two outlets were provided at the bottom level of the main channel and at the bottom of the tray to drain the surface and subsurface runoffs, respectively. The 
tray was placed on a $60 \mathrm{~cm}$ high metallic frame. An over-head sprinkler system, consisting of six nozzles connected to a PVC pipe, acted as a rainfall simulator. The nozzles were placed horizontally above the tray at a height of $125.0 \mathrm{~cm}$ (Fig. 1(b)). A centrifugal pump, coupled with a half horse power motor and supply pipe line was used to create artificial rainfall over the catchment. A device was used to intercept and divert the nozzles' discharge away from the catchment, when necessary.

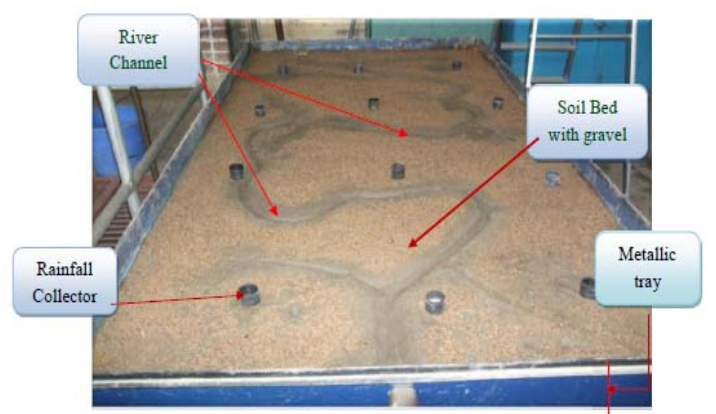

(a)



(b)

Fig. 1. Components of the hydrology bench: (a) soil filled metallic tray and (b) rainfall simulator

\section{Experimentation}

Before starting a set of experiments, the catchment was sprinkled with water by the rainfall simulator for about half an hour to make it wet. After the wetting period, the nozzles' discharge was diverted by the interceptor. The experiment was then started after cessation of the runoff generated by the preceding rainfall. Several sets of experiments were conducted to study the runoff generation process on the catchment. In a given set of experiments, the rainfall intensity remained constant, but effective rainfall duration varied.

At the initial stage of each experiment, the nozzles were allowed to spray over the catchment. When the first drop of surface runoff appeared at the outlet, the time of effective rainfall (represented by $\mathrm{T}_{\mathrm{e}}$ ) began. The time between the inception of rainfall and the appearance of surface runoff at the outlet, called the initial loss time, was represented by $T_{i}$. After $T_{i}$, the rainfall was continued according to the duration of effective rainfall $\left(T_{e}\right)$, set for the experiment. Both $T_{i}$ and $T_{e}$ were recorded for each experiment by a stop watch. After the runoff due to the first experiment ceased, a second experiment with different effective rainfall duration was initiated. In this way, four experiments were conducted with different durations of effective rainfall. It should be noted that, while several experiments with different durations of effective rainfall were conducted, the rainfall intensity remained unchanged. Rainfall intensities were varied by the check valve in the supply line and the procedure repeated for other sets of experiments.

\section{Data collection and processing}

Surface runoffs due to different effective rainfall durations for a given set of experiment were collected in bottles at specified pulses of time. The collected water in each time interval was weighed by an electronic balance and the volume calculated in ml. These were the 
constituents of surface runoff hydrograph due to the specified rainfall event. The summation of these values represented the total volume of surface runoff. This volume of surface runoff was divided by the area of the catchment to get the depth of direct runoff.

\section{Rainfall intensity}

After the experimental trials, twelve cylindrical pots (rainfall collectors) were placed on rectangular grids on the micro-catchment. The diameter and height of each pot were 3.55 and $3.00 \mathrm{~cm}$, respectively. Then the nozzles were allowed to spray on to the catchment for 10 minutes. The water collected in each pot was weighed and the volume calculated. Depth of catch in each pot was calculated by dividing the collected water by the catch area of the pot. Average depth of rainfall on the catchment in 10 minutes was calculated by taking arithmetic mean of the 12 catch depths. Rainfall intensity in $\mathrm{mm} / \mathrm{min}$ was then calculated.

\section{Unit Hydrograph (UH)}

Surface runoff rates in $\mathrm{ml} /$ time unit, collected in each experiment, constituted the ordinates of surface runoff hydrograph for the particular rainfall intensity and effective rainfall duration. These ordinates were divided by the depth of direct runoff $(\mathrm{mm})$ to get the unit hydrograph ordinates for the experiment.

\section{Recession constant}

The recession limb of a hydrograph begins from the point of inflection at the end of the crest segment. The shape of this limb is independent of the rainfall characteristics and depends entirely on the catchment characteristics (Subramanya, 2008). The most generally used function for describing recession curve is given by

$\mathrm{Q}_{1}=\mathrm{Q}_{0} \times \mathrm{K}^{\mathrm{t}}$

Where, $\mathrm{Q}_{0}=$ initial discharge, $\mathrm{Q}_{1}=$ the discharge at time $\mathrm{t}$ after $\mathrm{Q}_{0}$ and $\mathrm{K}$ is a recession constant whose value is less than unity. In this work, values of $\mathrm{K}$ were calculated from the recession curves through optimization.

\section{RESULTS AND DISCUSSION}

\section{Surface runoff}

Table 1 presents values of surface runoff volumes and surface runoff generation rates for different rainfall intensities and durations. The table shows that both the runoff volumes and runoff generation rates changed positively with the increase of rainfall duration. But the change in runoff generation rate was lower than that of runoff volume. This is also expected to happen because with increasing rainfall duration infiltration goes on decreasing, which results in increasing runoff generation rate. For a given duration, runoff volumes and generation rates were different in different rainfall intensities. These results indicate that there is an influence of rainfall intensity on runoff generation processes (Linsley et al., 1988) although no specific trend was identified. Total volume of runoff for each duration in set 1 was less than the corresponding values in other sets although rainfall 
intensity in set 1 was the maximum. This was so because the catchment was drier at the beginning of the experiments of set 1 than the other sets. Therefore, the rates of initial loss and continuing loss for set 1 were high. As a result, volume of surface runoff was low.

Table 1. Surface runoff volumes $(\mathrm{ml})$ and surface runoff generation rate (in parenthesis) $(\mathrm{mm} / \mathrm{min})$ for different effective rainfall durations

\begin{tabular}{|c|c|c|c|c|c|}
\hline \multirow[t]{2}{*}{ Set } & \multirow{2}{*}{$\begin{array}{l}\text { Rainfall intensity } \\
(\mathrm{mm} / \mathrm{min})\end{array}$} & \multicolumn{4}{|c|}{ Duration of effective rainfall(s) } \\
\hline & & 40 & 60 & 80 & 100 \\
\hline 1 & 0.62 & $\begin{array}{l}402.28 \\
(0.26)\end{array}$ & $\begin{array}{r}683.43 \\
(0.30)\end{array}$ & $\begin{array}{c}936.40 \\
(0.31)\end{array}$ & $\begin{array}{c}1231.31 \\
(0.32)\end{array}$ \\
\hline 2 & 0.60 & $\begin{array}{c}576.74 \\
(0.38)\end{array}$ & $\begin{array}{r}900.03 \\
(0.39)\end{array}$ & $\begin{array}{c}1204.34 \\
(0.40)\end{array}$ & $\begin{array}{c}1656.71 \\
(0.44)\end{array}$ \\
\hline 3 & 0.59 & $\begin{array}{c}488.93 \\
(0.32)\end{array}$ & $\begin{array}{c}732.62 \\
(0.32)\end{array}$ & $\begin{array}{c}1067.71 \\
(0.35)\end{array}$ & $\begin{array}{c}1375.59 \\
(0.36)\end{array}$ \\
\hline 4 & 0.56 & $\begin{array}{c}546.73 \\
(0.36)\end{array}$ & $\begin{array}{l}849.17 \\
(0.37)\end{array}$ & $\begin{array}{c}1264.11 \\
(0.42)\end{array}$ & $\begin{array}{c}1693.50 \\
(0.45)\end{array}$ \\
\hline 5 & 0.55 & $\begin{array}{c}387.48 \\
(0.26)\end{array}$ & $\begin{array}{r}689.61 \\
(0.30)\end{array}$ & $\begin{array}{c}1127.15 \\
(0.37)\end{array}$ & $\begin{array}{c}1445.88 \\
(0.38)\end{array}$ \\
\hline 6 & 0.50 & $\begin{array}{c}455.90 \\
(0.30)\end{array}$ & $\begin{array}{r}736.60 \\
(0.32)\end{array}$ & $\begin{array}{c}1003.94 \\
(0.33)\end{array}$ & $\begin{array}{c}1384.63 \\
(0.36)\end{array}$ \\
\hline
\end{tabular}

The peak flow rates and peak flow rates per second of effective rainfall duration are presented in Table 2. The latter was calculated by dividing the peak rate by the corresponding effective rainfall duration. These show that the peak flow rate of runoff increased with the increase of effective rainfall duration. This change is very much obvious according to the concept of hydrograph. But it is notable that per sec peak flow rates for each rainfall intensity decreased with the increase of duration. This can be explained with the S-curve concept where it is learned that after certain time of a continuous rainfall on a catchment, runoff flow rate will reach a constant value. After that, flow will no more increase even though rainfall duration is further increased. Before reaching this constant flow condition, peak flow rate will obviously increase with the increase of rainfall duration but at a reduced rate. In other words, peak flow rate per sec of effective rainfall will decrease with the increase of duration.

\section{Unit hydrographs $(\mathrm{UH})$}

Unit hydrographs resulting from 4 different durations are superimposed in Fig. 2 for the 6 rainfall intensities. These show that the UH peak decreased and time base increased with the increase of effective rainfall duration. This is expected to happen because, in case of unit hydrograph, it is assumed that for a given intensity of rainfall, the same quantity of runoff (unit quantity) flows through the catchment in different rainfall durations. As the duration increases, the intensity of runoff generation decreases, resulting in a reduced peak and an elongated time base. 


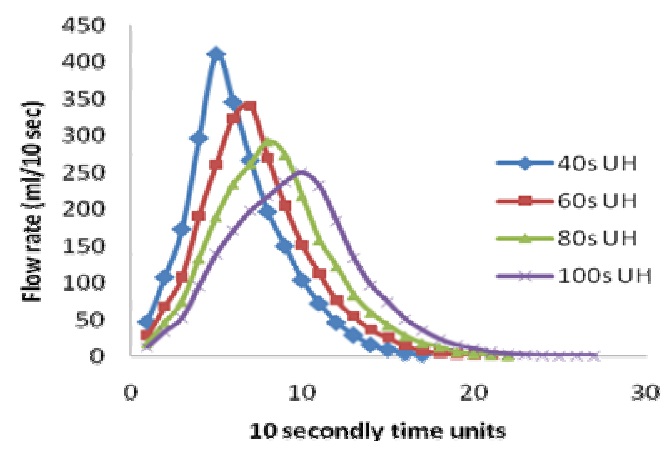

(a) Set 1

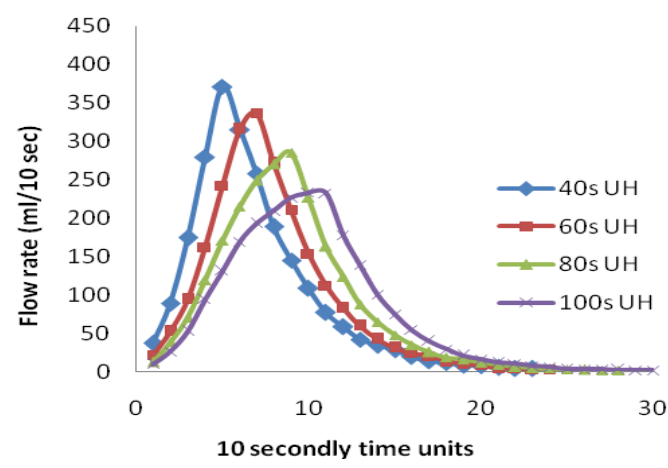

(c) Set 3

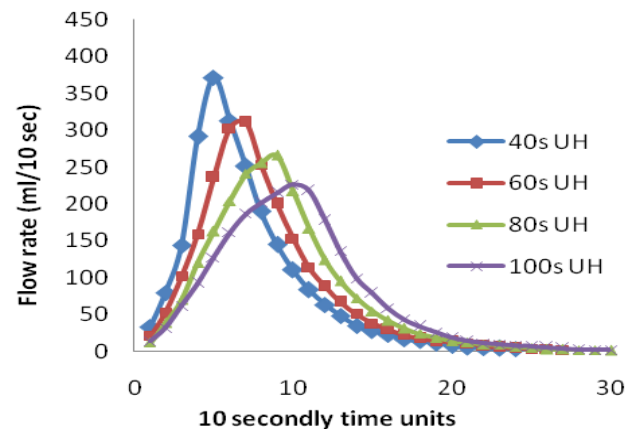

(e) Set 5

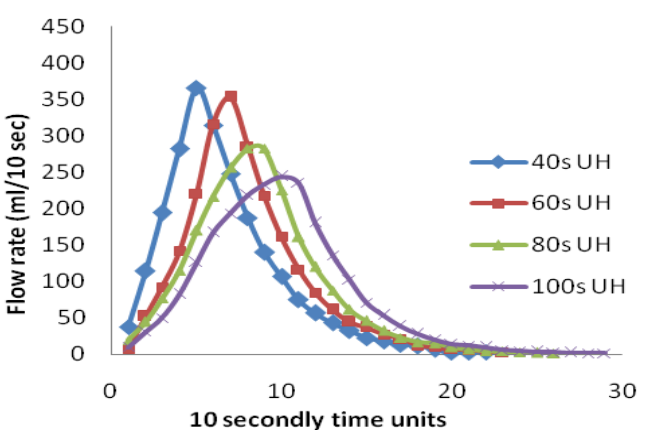

(b) Set 2

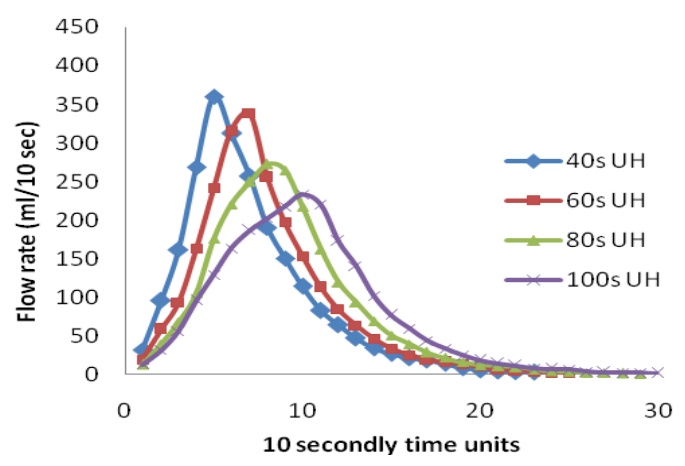

(d) Set 4

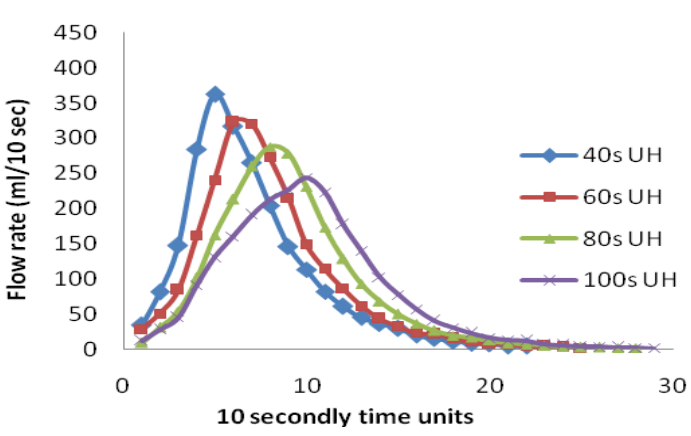

(f) Set 6

Fig. 2. Comparison of unit hydrographs for different rainfall intensities

For each duration, unit hydrographs from different rainfall intensities are superimposed in Fig. 3. Unit hydrographs of a given duration followed almost the same pattern with peaks occurring at the same time. This result is in good agreement with the assumptions of unit hydrograph. However, some variations in the magnitudes of peak for a given duration are observed. This might be attributed to the variations of rainfall distribution over the catchment in different intensity scenarios which was not measured in this study. This also shows that for a given duration the shapes of the unit hydrographs are preserved. This justifies the use of unit hydrograph in rainfall-discharge transformation. 
Table 2. Peak flow rate $(\mathrm{ml} / 10 \mathrm{~s})$ and peak flow rate per second of effective rainfall duration (in parenthesis) in $(\mathrm{ml} / 10 \mathrm{~s}) / \mathrm{s}$

\begin{tabular}{|c|c|c|c|c|c|}
\hline \multirow[t]{2}{*}{ Set } & \multirow{2}{*}{$\begin{array}{l}\text { Rainfall intensity } \\
(\mathrm{mm} / \mathrm{min})\end{array}$} & \multicolumn{4}{|c|}{ Duration of effective rainfall (s) } \\
\hline & & 40 & 60 & 80 & 100 \\
\hline \multirow[t]{2}{*}{1} & 0.62 & 72.46 & 101.79 & 119.76 & 134.87 \\
\hline & & $(1.81)$ & $(1.70)$ & $(1.50)$ & (1.35) \\
\hline \multirow[t]{2}{*}{2} & 0.60 & 93.30 & 128.52 & 150.17 & 170.12 \\
\hline & & $(2.33)$ & $(2.14)$ & $(1.88)$ & $(1.70)$ \\
\hline \multirow[t]{2}{*}{3} & 0.59 & 79.69 & 108.23 & 133.41 & 140.72 \\
\hline & & (1.99) & $(1.80)$ & $(1.67)$ & $(1.41)$ \\
\hline \multirow[t]{2}{*}{4} & 0.56 & 86.47 & 126.09 & 151.07 & 173.14 \\
\hline & & $(2.16)$ & $(2.10)$ & $(1.89)$ & $(1.73)$ \\
\hline \multirow[t]{2}{*}{5} & 0.55 & 62.28 & 106.83 & 139.61 & 154.83 \\
\hline & & $(1.56)$ & $(1.78)$ & $(1.75)$ & $(1.55)$ \\
\hline \multirow[t]{2}{*}{6} & 0.50 & 72.46 & 104.31 & 126.66 & 147.95 \\
\hline & & (1.81) & $(1.74)$ & $(1.58)$ & $(1.48)$ \\
\hline
\end{tabular}

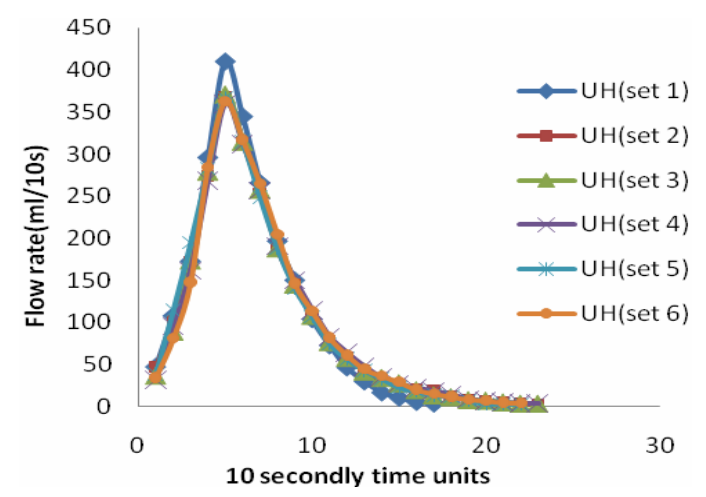

(a) $\mathrm{UH}$ of $40 \mathrm{sec}$ effective rainfall duration

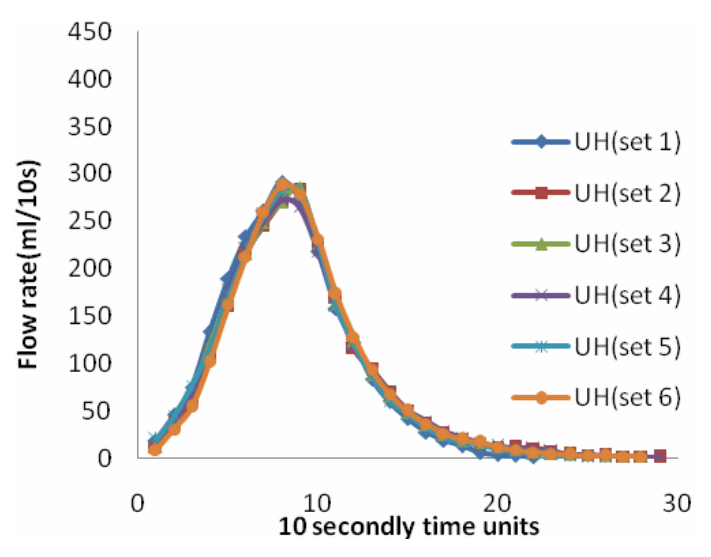

(c) UH of 80 s effective rainfall duration

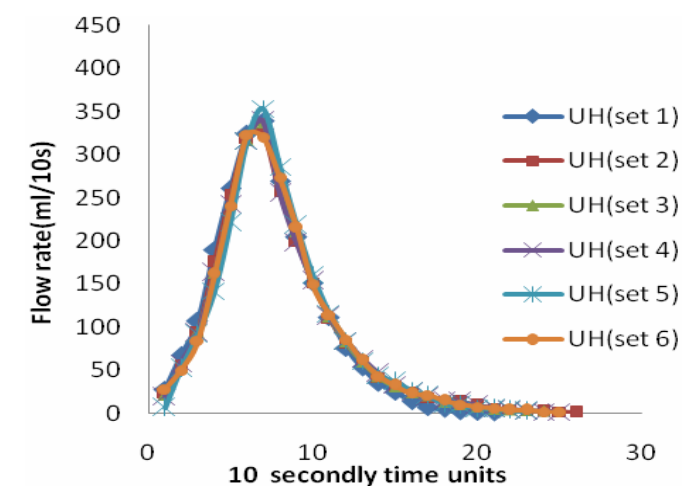

(b) UH of $60 \mathrm{sec}$ effective rainfall duration

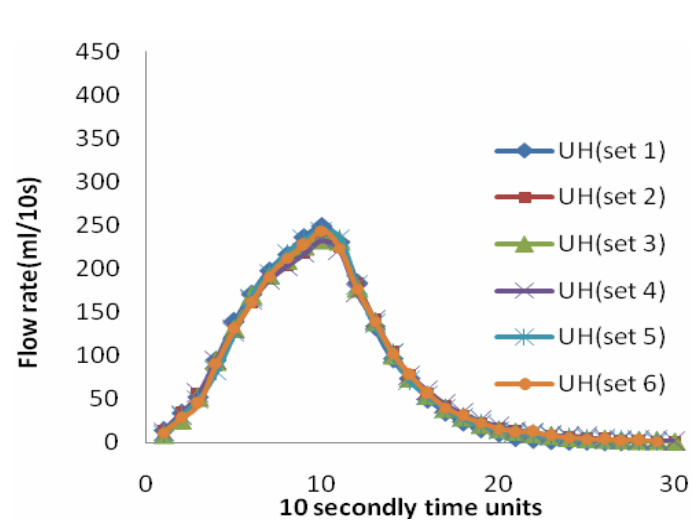

(d) $\mathrm{UH}$ of 100 s effective rainfall duration

Fig. 3. Unit hydrograph (UH) of different rainfall durations 


\section{Recession constant}

Values of recession constant $\mathrm{K}$ for hydrographs of different durations and intensities of rainfall are presented in Table 3 . The values of $\mathrm{K}$ vary from 0.725 to 0.772 .

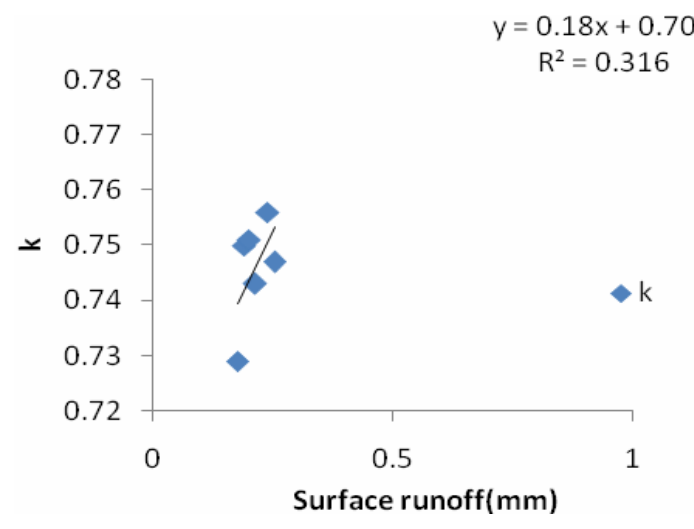

(a) 40 s effective rainfall duration

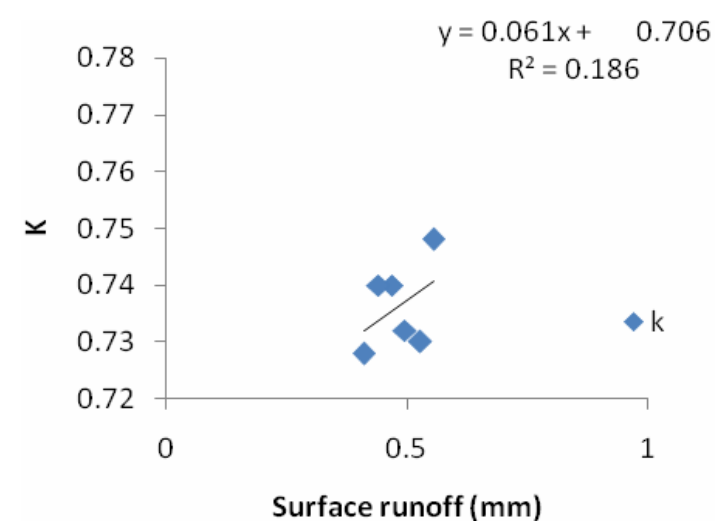

(c) 80 s effective rainfall duration

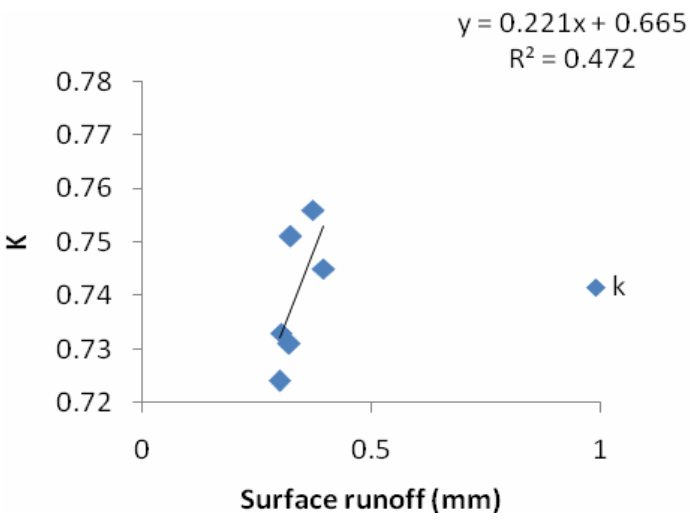

(b) 60 s effective rainfall duration

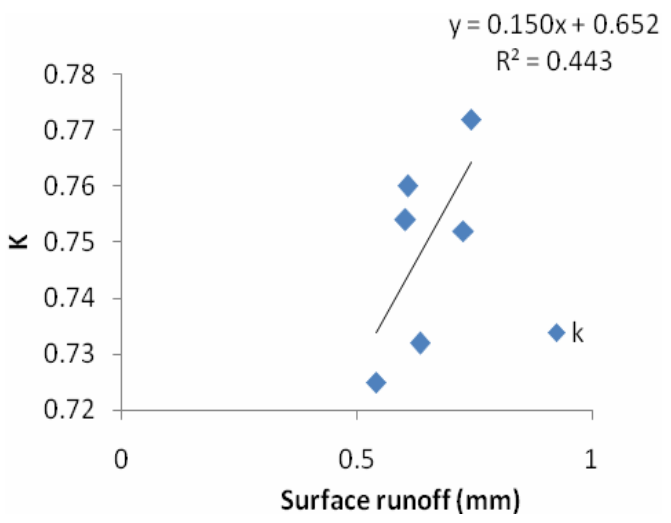

(d) $100 \mathrm{~s}$ effective rainfall duration

Fig. 4. Relation between recession constant $\mathrm{K}$ and surface runoff volumes for different rainfall durations

Table 3. Values of the recession constant, $\mathrm{K}$, of surface runoff hydrographs of different durations and rainfall intensities

\begin{tabular}{c|c|c|c|c|c}
\hline Set & Rainfall intensity & \multicolumn{4}{|c}{ Duration of effective rainfall (s) } \\
\cline { 3 - 5 } & $(\mathrm{mm} / \mathrm{min})$ & $\mathbf{4 0}$ & $\mathbf{6 0}$ & $\mathbf{8 0}$ & $\mathbf{1 0 0}$ \\
\hline 1 & 0.62 & 0.730 & 0.724 & 0.728 & 0.725 \\
2 & 0.60 & 0.746 & 0.745 & 0.730 & 0.752 \\
3 & 0.59 & 0.743 & 0.731 & 0.740 & 0.754 \\
4 & 0.56 & 0.746 & 0.756 & 0.748 & 0.772 \\
5 & 0.55 & 0.750 & 0.733 & 0.732 & 0.732 \\
6 & 0.50 & 0.752 & 0.751 & 0.740 & 0.760 \\
\hline
\end{tabular}


For each effective rainfall duration, $\mathrm{K}$ values are plotted against runoff volumes in Fig. 4 . These plots show a positive relationship between $\mathrm{K}$ and runoff volume, though the relationship is not pronounced for the effective rainfall duration of 80 seconds. This suggests that the shape of the recession is not completely a function of basin characteristics, but also depends, to some extent, on the rainfall characteristics. This result contradicts the assumption that the recession is independent of the characteristics of the storm causing runoffs (Linsley et al., 1988).

\section{CONCLUSIONS}

The hydrology bench was satisfactorily used in this study to simulate the rainfall-runoff system in the laboratory. The variations of runoff volume, runoff rate and peak flow rate for a given rainfall intensity under different rainfall durations establish a consistent relations that support the already established rainfall-runoff relations. No consistent relations are found considering the effect of various rainfall intensities under constant duration. Unit hydrographs for a given duration derived from different rainfall events produce the same shape of direct runoff hydrograph. It says that the assumption of linearity between runoff volume and hydrograph ordinates, which is the basis of unit hydrograph concept, is found to be valid. This study also reveals that the recession hydrograph is not only a function of catchment characteristics but also of rainfall intensities. The result would be more satisfactory if the runoff volumes were collected at shorter pulses of time ( $<10$ seconds). Further studies can be conducted to quantify rainfall-runoff processes by introducing different conditions of vegetative cover on the catchment.

\section{REFERENCES}

Joshi, V. E. and Tambe, D. T. 2010. Estimation of infiltration rate, run-off and sediment yield under simulated rainfall experiments in upper Pravara Basin, India: Effect of slope angle and grasscover. J. Earth Syst. Sci., 119, 6: 763-773.

Linsley, Jr. R. K., Kogler, M. A., Paulhus, J. L. H. and Wallace, J. S. 1988. Hydrology for Engineers. McGrow- Hill Book Company, p. 193.

Pan, C. and Shangguan, Z. 2006. Runoff hydraulic characteristics and sediment generation in sloped grassplots under simulated rainfall conditions. J. Hydrology, 331: 178-185.

Sayed, E. A. and Habib, E. 2008. Advanced technique for rainfall-runoff simulation in arid catchments, Sinai, Egypt. The 3rd International Conference on Water Res. and Arid Env. and the 1st Arab Water Forum. 1-14.

Subramanya, K. 2008. Engineering Hydrology. Tata McGraw Hill Publishing Company Limited, New Delhi. $3^{\text {rd }}$ edn, pp. 155-159. 